\title{
Abridged Acid-Base Wet-Milling Synthesis of High Purity Hydroyapatite
}

\author{
Sandi Carolina Ruiz-Mendoza, Luis Carlos Moreno-Aldana, Edgar Delgado-Mejía*
}

\author{
Departamento de Química, Grupo de Aplicaciones de Materiales a la Odontología - GRAMO, \\ Universidad Nacional de Colombia, \\ Avenida Carrera, 30 no. 45-03, Bogotá, Colombia
}

Received: February 8, 2008; Revised: May 28, 2008

\begin{abstract}
There is a plethora of routes to produce hydroxyapatite(HA) and in general calcium phosphates(CP) but production usually leads to a mixture of several phases. Besides ionic contamination, most of these methods are cumbersome, restricted to small volumes of product and require a lot of thermal energy. The acid-base route eliminates foreign ions or additives and its only byproduct is water. Heterogeneous reaction drawback is that solid reactants do not easily come in contact with each other and therefore addition and stirring times become very lengthy and still the product is a mixture.

The synthesis started from calcium hydroxide and phosphoric acid (PA). Ball milling was used to favor kinetics and stoichiometry. Six sets of PA addition, paddle stirring and ball milling times were used. Products were evaluated by X ray diffraction (XRD), Fourier Transform Infrared (FTIR), scanning electron microscopy $(\mathrm{SEM}), \mathrm{X}$ ray fluorescence $(\mathrm{XRF})$ and $\mathrm{Ca} / \mathrm{P}$ ratio. Chemical analysis for calcium proceeded through oxalate precipitate and phosphorus by the phosphomolibdate technique. A set of conditions yielding high purity HA was established.
\end{abstract}

Keywords: hydroxyapatite synthesis, high purity hydroxyapatite, mechanosynthesis

\section{Introduction and Literature Review}

CPs are the most abundant inorganic constituent of living beings hard tissues. This inorganic part provides bone and teeth with hardness, density and mechanical stability. $\mathrm{HA}\left(\mathrm{Ca}_{10}\left(\mathrm{PO}_{4}\right)_{6}(\mathrm{OH})_{2}\right)$ is the main $\mathrm{CP}$ present in these tissues ${ }^{1,2}$.

Hypomineralization, fractures and many pathologies make necessary the reinforcement or substitution of hard tissues with various CPs among which HA plays a central role. Injuries and disease treatments for improving or restoring body functions require also the use of metallic plates, wires and screws as well as calcium phosphates based cements for adhesion or gap filling ${ }^{2-8}$. HA is the main or one of the major starting components for these biomaterials and usually the main final phase after physicochemical and biological processes. Therefore it is important to count on a reliable, expedite method for producing inexpensive abundant pure HA.

There are many synthetic routes and preparation methods for HA. There is also a large variability of products with several CPs contaminants present, fact that demonstrates how difficult it is to obtain pure stoichiometric $\mathrm{HA}^{7}$. Several methods belong in the most used techniques, namely wet synthesis, solid state reaction, sol-gel process, sonochemical synthesis and the hydrothermal route ${ }^{7-17}$. A couple of these methods are able to produce pure HA but their yield is low compared to the mass and volume used ( 5 to $14.8 \mathrm{~g}$ of product per $100 \mathrm{~mL}$ of initial reaction volume).

Almost all of the commercially available CPs are mixtures of several phases and many contain foreing elements. Some of the common methods rely on CPs compounds for producing HA. This strategy just postpones the problem without solving it, otherwise the starting CP has to be synthesized without contamination in order to calculate precise proportions for a defined reaction. For instance solid monocalcium phosphate monohydrate (MCPM) can be reacted at $1200{ }^{\circ} \mathrm{C}$ with solid $\mathrm{CaCO}_{3}$ to produce $\mathrm{HA}$ but MCPM usually contains phosphoric acid, some dicalcium phosphate dihydrate (DCPD) and probably anhydrous monocalcium phosphate (MCPA). In this way the time to produce HA has to include the synthesis and characterization of pure MCPM.

Synthesis in solution imply foreign ions since most calcium salts are sparingly soluble and only a few like nitrates, chlorides or acetates are suitable for this method. In order to displace foreign anions, phosphorus is supplied as a salt, usually sodium, potassium or ammonium salts and hence non $\mathrm{CPs}$ such as $\mathrm{NaCl}$ or sodium acetate are formed. Organic anions can be burnt off. Ammonium nitrate seems to leave no residue. Filtering is often an inapropiate practice because once the CP sediment is formed most methods separate the mother liquor from the solid by decantation or filtration. This supernatant contains most of the soluble foreign salts plus an incongruent concentration of calcium and phosphorus that deviate the solid stoichiometry generating extraneous phases. Solid state route relies on CPs and very prolonged heating, milling, pelletizing and reheating cycles in order to achieve homogeneity and complete reaction.

The sol-gel method has advantages for instance final particle size and coating forming capabilities but the high cost and low content of organometallic precursors are noticeable as well as its chemical instability. Hydrothermal conditions are limited because of the internal useful volume of the reactor.

One of the starting points where the almost inherent CPs phase contamination can be avoided is to use non CPs sources of calcium and phosphorus namely $\mathrm{Ca}(\mathrm{OH})_{2}$ and $\mathrm{H}_{3} \mathrm{PO}_{4}$ so that the only byproduct is water, is a very clean reaction (Equation 1). Calcium hydroxide is only slightly soluble and if the solution approach is to be applied then quite large volumes of very dilute solutions must be used and small amounts of HA will be obtained. Since productivity is a must then high solid to liquid ratio suspensions should be used. The main 
drawback of this heterogeneous systems is that the reaction does not proceed easily to the desired and calculated product because of mass transfer restrictions in and around insoluble calcium hydroxide grains (Figure 1). Acidic sparingly soluble CPs (mainly dicalcium phosphate dihydrate or DCPD) are rapidly formed on the surface of calcium hydroxide grains engulfing the unreacted core and hindering further reaction. Composition of solution surrounding grains is ruled by this non HA acidic CPs whose solubility product constant is huge compared to that of HA $(-\operatorname{logKsp}=6.59$ for DCPD and 116.8 for HA at $25^{\circ} \mathrm{C}^{1}$ ) and also the $\mathrm{Ca} / \mathrm{P}$ ratio in solution is different from 1.67 (1.0 for DCPD) and therefore filtration should be avoided to maintain precise reactants proportions for a preselected product. While acidic CPs are on the outer layers, unreacted calcium hydroxide and basic CPs lie inside. Careful attention was exerted to dodge any unwanted deviation in stoichiometry caused by processes such as filtering.

The primary purpose of this work was to establish the relative importance of addition, stirring and ball milling times on final product content indicating the capability to break or disperse the grains. Breaking facilitates access for acid-base reaction to proceed. The final purpose was to attain a brief and easy method for obtaining high purity HA.

\section{Experimental Procedure}

\subsection{HA synthesis}

United States Pharmacopoeia (USP) grade calcium carbonate (content $>99 \%$ ) was heated to constant weight at $900{ }^{\circ} \mathrm{C}$ ( 3 hours) to obtain calcium oxide that was kept in a desiccator and finally carefully weighed. Recently boiled cool deionized water was carefully mixed in under mechanical paddle stirring with calcium oxide to give a thick calcium hydroxide suspension. Splatter caused by intense heat evolution was controlled using deionized ice and cool water inside the vessel that was partially submerged in ice water. For methods one through five $295 \mathrm{~g}$ of calcium hydroxide were contained in $400 \mathrm{~mL}$ deionized water, $(\mathrm{S} / \mathrm{L}$ ratio 0.74$)$. Without delay 161.0 $\mathrm{mL}$ of analytical reagent grade orthophosphoric acid solution $(85 \%$, Merck $^{\circledR}$ ) previously titrated with $\mathrm{NaOH}$ was poured or dropwise added on the calcium hydroxide slurry following the six methods described below. The proper stoichiometric weights were calculated based on Equation 1

$$
10 \mathrm{Ca}(\mathrm{OH})_{2}+6 \mathrm{H}_{3} \mathrm{PO}_{4} \rightarrow \mathrm{Ca}_{10}\left(\mathrm{PO}_{4}\right)_{6}(\mathrm{OH})_{2}+18 \mathrm{H}_{2} \mathrm{O}
$$

Methods were numbered 1 through 6 (M1, M2 ...,M6), the product of each method was labeled HA1 for method 1 and so on.

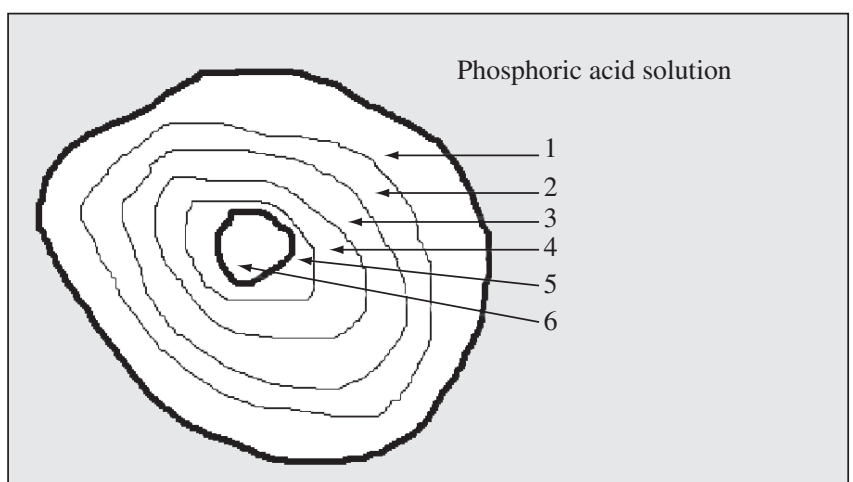

Figure 1. Partially reacted $\mathrm{Ca}(\mathrm{OH})_{2}$ grain structure with concentration gradient layers. $\mathrm{H}_{3} \mathrm{PO}_{4}$ solution is background. Zone 1 is rich in phosphate, zone 6 is rich in calcium probably calcium hydroxide. $\mathrm{Ca} / \mathrm{P}$ ratio increases going inward.
M1 with many small variations is perhaps the most widely used wet route $\operatorname{method}^{7}$ and here it was included as a starting point and as a comparison. The six methods were:

M1) PA dropwise addition during 6 hours $(0.45 \mathrm{~mL}$ per minute) on the stirred aqueous calcium hydroxide suspension mixing with a teflon blades stirrer for 18 hours more. The product was named HA1;

M2) Rapid PA addition (13 minutes equivalent to $12.38 \mathrm{~mL}$ per minute) over the calcium hydroxide slurry with stirring for 24 hours including the addition time;

M3) One hour PA addition on calcium hydroxide stirred suspension followed by 1 hour wet ball milling;

M4) PA addition in 1 hour over stirred calcium hydroxide slurry and 6 hours ball milling;

M5) Rapid PA addition (13 minutes) on stirred calcium hydroxide suspension plus 6 hours ball milling. Solid calcium hydroxide to deionized water weight ratio (S/L) was 0.74 ; and

M6) The same as M5 but solid to water ratio was 1.18 $(295 \mathrm{~g} / 250 \mathrm{~mL})$.

Milling was conducted with alumina balls in a jar mill fitted with a porcelain ceramic tank rotating at $58 \mathrm{rpm}$. Transfer from reaction vessel to milling tank was done quantitatively for supernatant and solids without wasting any reactant but keeping rinsing water volume as small as possible. Milled slurries were transferred into platinum crucibles for drying and firing with lid on. Resulting HA was dried at $100-110{ }^{\circ} \mathrm{C}$ for 2 hours and sintered for 4 hours at $1000{ }^{\circ} \mathrm{C}$.

\subsection{Characterization}

Dry unsintered HA (indicated by nsHA1 through nsHA6) and sintered HA samples (sHA1 through sHA6) were subjected to XRD (Philips type PW 1820 Based diffractometer, copper anode, $40 \mathrm{KV}$, $30 \mathrm{~mA}, \lambda=1.54181 \mathrm{~nm}$.), FTIR (Perkin Elmer Paragom 500) and their $\mathrm{Ca} / \mathrm{P}$ molar ratios were assessed by chemical wet analysis.

Calcium was measured by precipitating calcium as oxalate, dissolving it with sulfuric acid and titrating with standardized $\mathrm{KMnO}_{4}$ solution. Phosphorus content was also volumetrically measured by precipitating phosphorus as ammonium phosphomolibdate, dissolving the yellow precipitate with $\mathrm{NaOH}$ and finally titrating excess sodium hydroxide with standardized hydrochloric acid solution ${ }^{18,19}$. Results are the media of three determinations for $\mathrm{Ca}$ and three for $\mathrm{P}$ in each of the samples.

Particle size was measured by laser dispersion (Cilas 1064) for green dry HA suspended in $96 \%$ ethanol with 60 seconds ultrasonication prior to reading. Particle size of sHA depends on temperature and sintering time, contact area, pressure and many other factors as well as manually breaking HA lumps, so it was not measured but estimated from scannig electron microscopy (SEM). Basic crystallite size was calculated by means of Equation 2:

$$
\mathrm{L}=\frac{\mathrm{k} \lambda}{\beta \cos \theta}
$$

$\mathrm{k}=0.9 ; \beta=$ peak width at half height of main XR signal. $\lambda_{\mathrm{Cu}}=1.54181 \mathrm{~nm}$.

The effect of milling contamination on elemental composition was assessed by XRF semiquantitative analysis (Philips ${ }^{\circledR}$ Magic X PRO PW 2440/00) on $40 \mathrm{~mm}$ diameter disks pressed with calcium hydroxide or sHA6 powder and spectroscopic wax tabletting aid (Merck-Hoechst ${ }^{\circledR}$ ).

\section{Results and Discussion}

XRD peaks were assigned after careful comparison with XRD data ${ }^{7,8,20}$ for possible $\mathrm{CP}$ compounds as follows : $\mathrm{Ca}_{10}\left(\mathrm{PO}_{4}\right)_{6}(\mathrm{OH})_{2}$ or 
$\mathrm{HA}, \alpha-\mathrm{Ca}_{3}\left(\mathrm{PO}_{4}\right)_{2}$ or alfa tricalcium phophate $(\alpha-\mathrm{TCP}), \beta$-TCP (here simplified to TCP on XRD patterns), $\mathrm{Ca}(\mathrm{OH})_{2}, \mathrm{CaO}, \mathrm{Ca}\left(\mathrm{H}_{2} \mathrm{PO}_{4}\right)_{2} \cdot \mathrm{H}_{2} \mathrm{O}$ monocalcium phosphate monohydrate or $\mathrm{MCPM}, \mathrm{Ca}_{8} \mathrm{H}_{2}\left(\mathrm{PO}_{4}\right)_{6} \cdot 5 \mathrm{H}_{2} \mathrm{O}$ octacalcium phosphate (OCP), $\mathrm{CaHPO}_{4} \cdot 2 \mathrm{H}_{2} \mathrm{O}$ dicalcium phosphate dihydrate or DCPD, $\mathrm{Ca}\left(\mathrm{H}_{2} \mathrm{PO}_{4}\right)_{2}$ monocalcium phosphate anhydrous or MCPA, $\mathrm{Ca}_{4}\left(\mathrm{PO}_{4}\right)_{2} \mathrm{O}$ tetracalcium phosphate or TetCP, carboapatite $\mathrm{Ca}_{10}\left(\mathrm{PO}_{4}\right)_{3}\left(\mathrm{CO}_{3}\right)_{3}(\mathrm{OH})_{2}$ and $\mathrm{CaHPO}_{4}$ dicalcium phosphate anhydrous or DCPA. Five phases (HA, $\beta-\mathrm{TCP}, \mathrm{Ca}(\mathrm{OH})_{2}, \mathrm{CaO}$ and monocalcium phosphate anhydrous) were identified by comparison with JCPDS files 09-0432, 09-0169, 04-733, 037-1497 and 09-080 respectively ${ }^{20}$.
Figures 2 and 3 show the diffractograms for nsHA1 to 6 . As seen, before firing there are always four detected phases. Equations 3 through 6 may proceed simultaneously. TCP and DCPA are incomplete reaction products. Calcium hydroxide is remaining reactant.

$$
\begin{aligned}
& 2 \mathrm{CaHPO}_{4}+\mathrm{Ca}(\mathrm{OH})_{2} \rightarrow \mathrm{Ca}_{3}\left(\mathrm{PO}_{4}\right)_{2}+2 \mathrm{H}_{2} \mathrm{O} \\
& 6 \mathrm{CaHPO}_{4}+4 \mathrm{Ca}(\mathrm{OH})_{2} \rightarrow \mathrm{Ca}_{10}\left(\mathrm{PO}_{4}\right)_{6}(\mathrm{OH})_{2}+6 \mathrm{H}_{2} \mathrm{O} \\
& 2 \mathrm{Ca}_{3}\left(\mathrm{PO}_{4}\right)_{2}+2 \mathrm{CaHPO}_{4}+2 \mathrm{Ca}(\mathrm{OH})_{2} \rightarrow \\
& \mathrm{Ca}_{10}\left(\mathrm{PO}_{4}\right)_{6}(\mathrm{OH})_{2}+2 \mathrm{H}_{2} \mathrm{O}
\end{aligned}
$$

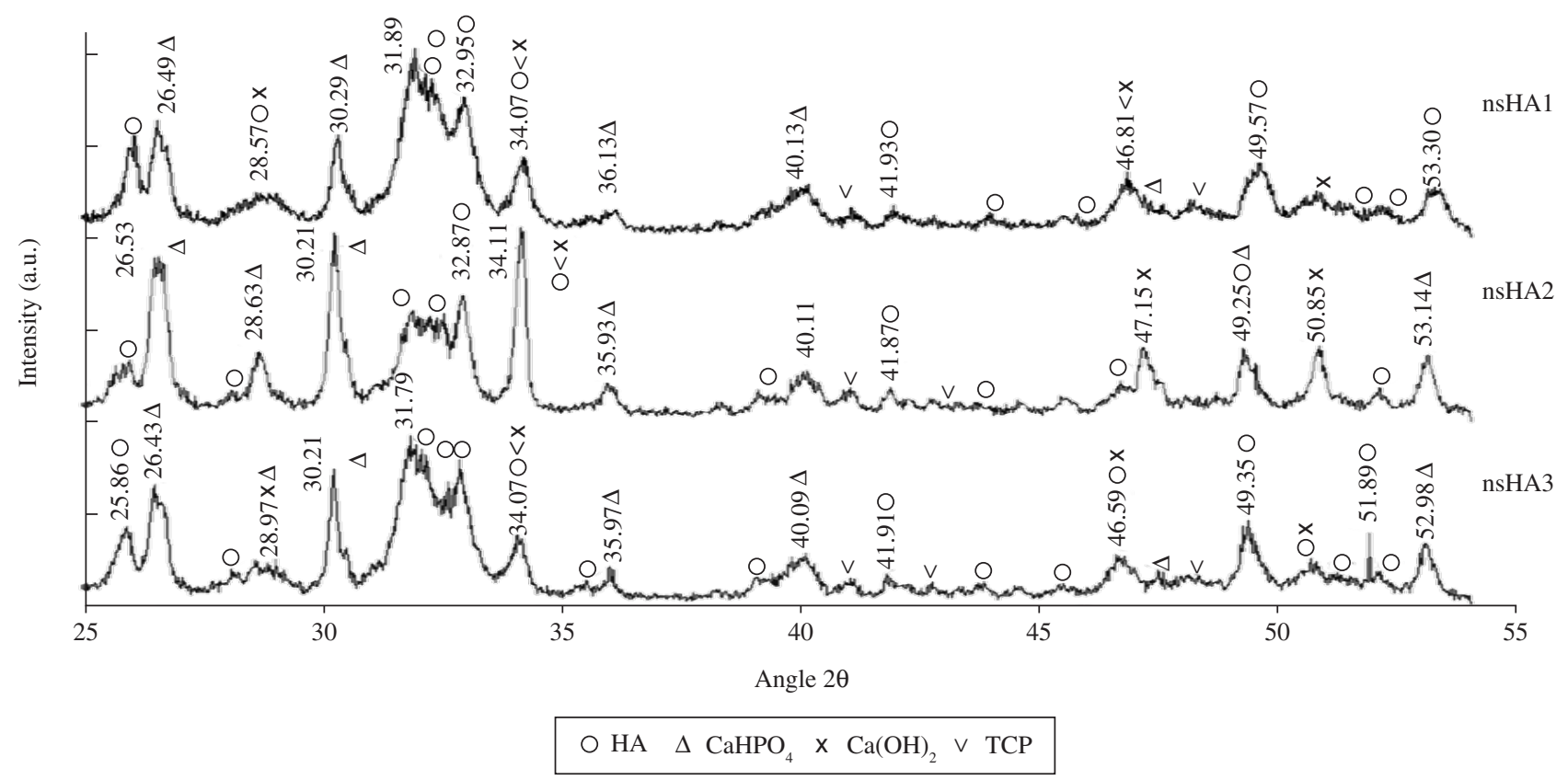

Figure 2. XRD patterns of non sintered HA 1, 2 and 3.

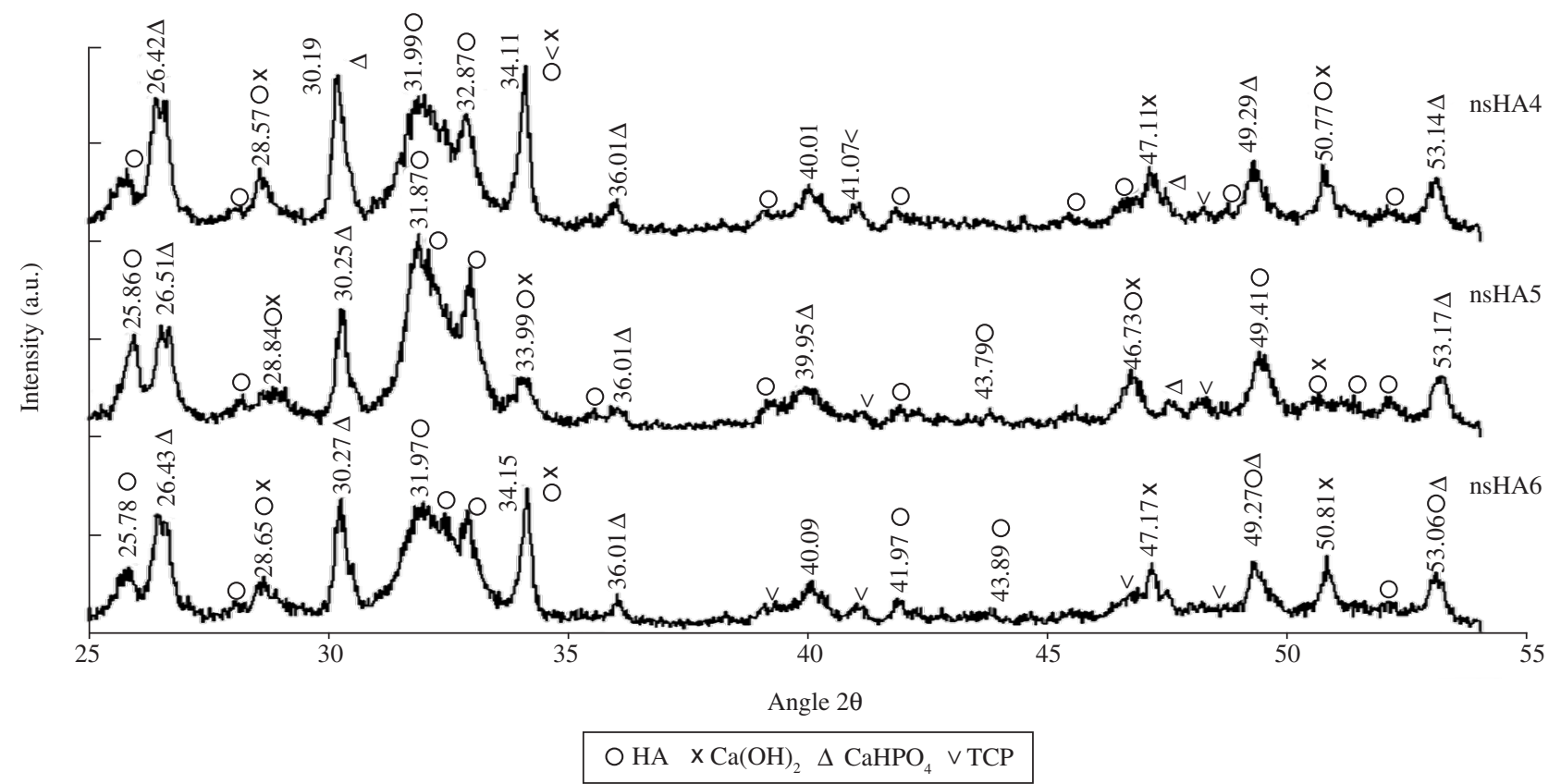

Figure 3. XRD patterns of non sintered HA 4, 5 and 6. 


$$
\begin{aligned}
& 6 \mathrm{Ca}_{3}\left(\mathrm{PO}_{4}\right)_{2}+2 \mathrm{Ca}(\mathrm{OH})_{2} \rightarrow 2 \mathrm{Ca}_{10}\left(\mathrm{PO}_{4}\right)_{6}(\mathrm{OH})_{2} \\
& \mathrm{Ca}(\mathrm{OH})_{2} \rightarrow \mathrm{CaO}+\mathrm{H}_{2} \mathrm{O} \\
& \mathrm{Ca}_{10}\left(\mathrm{PO}_{4}\right)_{6}(\mathrm{OH})_{2}+2 \mathrm{CaHPO}_{4} \rightarrow 4 \mathrm{Ca}_{3}\left(\mathrm{PO}_{4}\right)_{2}+2 \mathrm{H}_{2} \mathrm{O}
\end{aligned}
$$

\subsection{Unsintered products}

By comparison of peaks between 30 and 35 degrees for nsHA1 and 2 (Figure 2) it can be seen that slower acid addition (M1) favors the formation of $\mathrm{HA}$ and shorter times (M2) favor $\mathrm{CaHPO}_{4}$ and TCP. The fact that M1 and M2 used the same total stirring scheme ( 24 hours) but different addition times implies the latter exerts a stronger effect.

In this regard, patterns for nsHA 1 and nsHA 3 show that method 1 ( 6 hours acid addition +18 hours stirring) seems to be slightly better than M3 (1 hour addition +1 hour milling). Observing nsHA2 and 3 it can be seen that $1 \mathrm{~h}$ addition (M3) works out better than quick addition (13 minutes in M2). The influence of milling time can be inferred from nsHA4's diffractogram which displays lower HA peaks than expected when keeping in mind nsHA3. This can be interpreted in terms of a small milling effect. Nevertheless as discussed below, the content of pure HA after burning is not directly related to HA content in unsintered samples. When intending to increase the HA content in non sintered material it would seem important to proceed with a slow addition of PA and very lengthy stirring times.

\subsection{Sintered products}

Inspection of diffractograms for sintered products (Figures 4 and 5) makes clear that thermal treatment has reduced the phases to three. $\mathrm{CaHPO}_{4}$ has disappeared probably through reactions 3 to 5

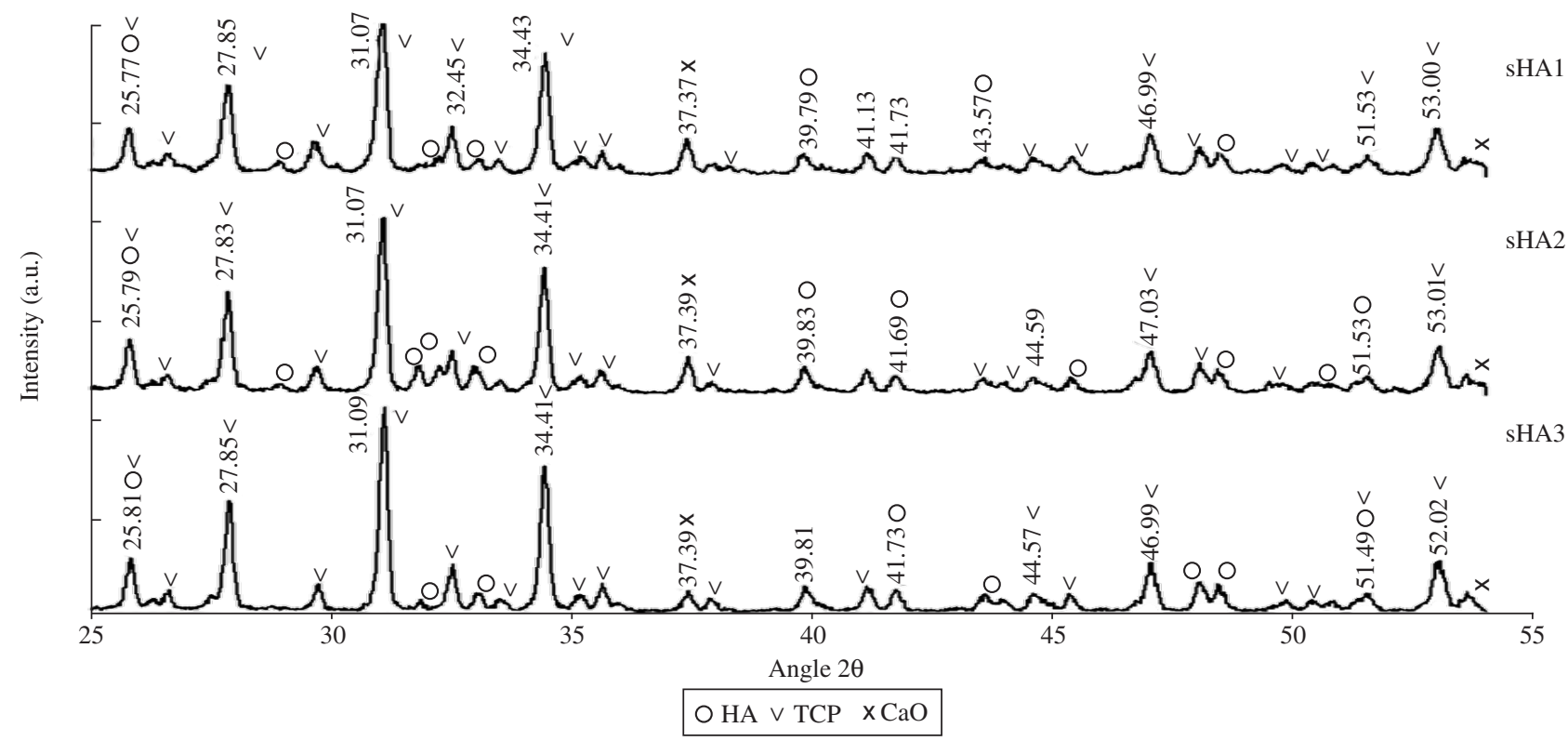

Figure 4. XRD patterns of sintered products from methods 1, 2 and 3.

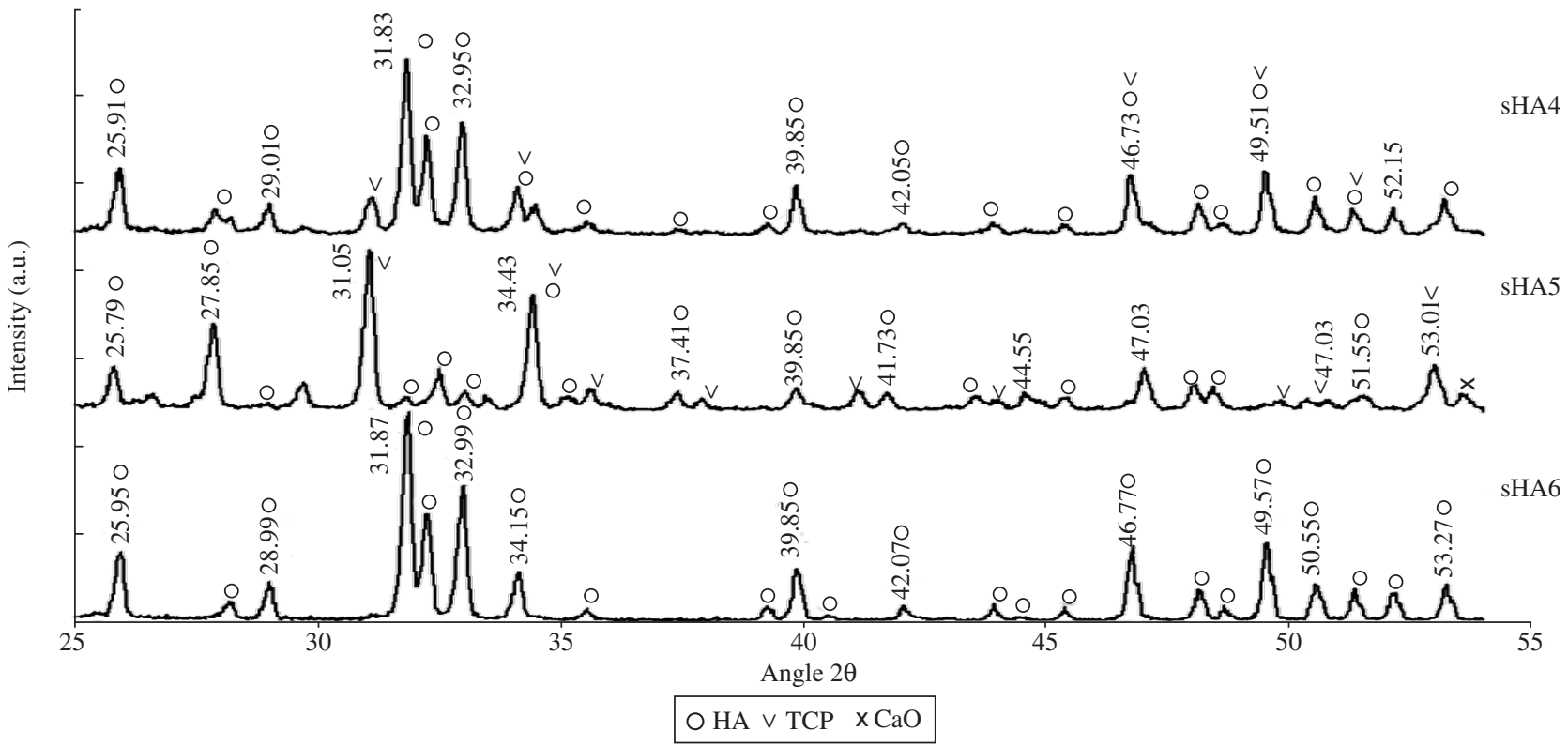

Figure 5. XRD patterns of sintered products from methods 4, 5 and 6 . 
rendering either TCP (M1, M2, M3, M5) or HA (M4, M6) as the main DRX signals. Calcium hydroxide has dehydrated into calcium oxide (reaction 7). Whenever TCP displays the strongest peaks, there is also non reacted calcium oxide ( 237.39 degrees and far right peak in sHA1, 2, 3 and 5). In the patterns where HA's peaks are the strongest there is either very little calcium oxide (sHA4) or no calcium oxide (sHA6). TCP and calcium oxide should react following reaction 6 to yield HA but when those two chemical are not evenly distributed reaction is hindered.

It is interesting to note that non sintered patterns with HA strongest peaks can lead to a sintered product with TCP displaying the main peaks, see for instance nsHA1 and sHA1. Also, nsHA4 and nsHA6 do not outstand for HA intense peaks but once heated sHA4 and sHA6 exhibit an almost pure or pure HA diffractogram. An intense HA peak can become a TCP peak through reactions 3 and 8 . As stated above, TCP is present whenever calcium oxide is present, these two would react following reaction 6 but this does not happen because inhomogeneity does not allow it. Resulting homogeneity and probably particle size is the difference among methods and it is not noticeable until sintering makes it apparent.

M3 results indicate that 1 hour addition and 1 hour milling do not end in a suitable homogeneity. M4 shows that increasing milling to 6 hours achieves an almost pure sHA. Trials with longer milling did not show any improvement. Milling efficiency is probably restricted by the liquid fraction that dampers and absorbs balls collision energy

M5 (sHA5, Figure 5) makes clear that the effect of 6 hours milling is outweighed by the disadvantage of quick PA addition.

Since milling longer than 6 hour with M4 did not work then an increase in milling efficiency through solid to liquid ratio control was included in M6. Figure 5 sets forth a sHA6 without any XRD detectable contamination. The result of a pure monophasic sHA6 reveals that an increased solid to liquid ratio largely overcomes the deleterious effect of quick acid addition of M6 and results are even better than those of 1 hour PA addition of M4.

In an interesting approach some researchers ${ }^{17}$ used the same acidbase reaction for HA starting from an aqueous calcium hydroxide suspension stabilized with an ionic polymeric defflocculant (Darvan) to have up to $148 \mathrm{~g}$ calcium hydroxide per liter then following lengthy method 1 here described. That article has to rely on an assumed total elimination of the organic moiety as well as the ammonim counterion. In the present article about 1,180 g calcium hydroxide can be contained in a liter of water so productivity is in a proportion of nearly 8 to $1(1180 / 148)$, the studied method requires no filtration, less time and energy for drying and includes no extraneous ions or molecules, characteristic that might be of paramount importance in an endogenous implanted biomaterial. Contaminated product of M1 requires 24 hours while pure HA number 6 needs only 6 hours and 13 minutes. Whatever the method is calcium hydroxide preparation is advisable because even though it consumes time and energy it assures calcium hydroxide purity since its obtention starts from a stable compound of known composition (calcium carbonate). Commercial calcium hydroxide might contain foreign elements and depending on shelf life it can be wet and carbonated, so any way there is need to dry it and fire it.

Crystallite size calculated from main DRX peak for sHA6 was $6.64 \mathrm{~nm}$ and that estimated from SEM observations that obviously corresponds to aggregates was approximately $8 \mu \mathrm{m}$ (Figure 6).

Experimental $\mathrm{Ca} / \mathrm{P}$ molar ratios appear in Table 1.

These are all close to the theoretical value (1.666) even those corresponding to mixtures of various phases like sHA1, sHA3 or sHA5. The ratio is only an indication of global composition and does not imply presence of a certain phase or even phase purity because for instance, before reaction a solid mixture of 7 moles of calcium carbonate and 3 moles of MCPM calculated for producing stoichiometric $\mathrm{HA}$ yields a perfect $\mathrm{Ca} / \mathrm{P}=1.67$ if it is very uniform but there is no HA at all. Lower or higher ratios can be obtained the greater the heterogeneity is. This ratio here indicates that reactants were added in the right proportions and that there was little or no loss.

FTIR spectra of samples prepared in $\mathrm{KBr}$ pellets display (Figure 7) adsorption bands related to $\mathrm{OH}$ ion stretching $\left(3571 \mathrm{~cm}^{-1}\right)$

Table 1. Experimental molar $\mathrm{Ca} / \mathrm{P}$ ratios of sintered products.

\begin{tabular}{cc}
\hline Sample & Molar Ca/P. \\
\hline sHA1 & 1.65 \\
sHA2 & 1.64 \\
sHA3 & 1.66 \\
sHA4 & 1.64 \\
sHA5 & 1.66 \\
sHA6 & 1.67 \\
\hline
\end{tabular}

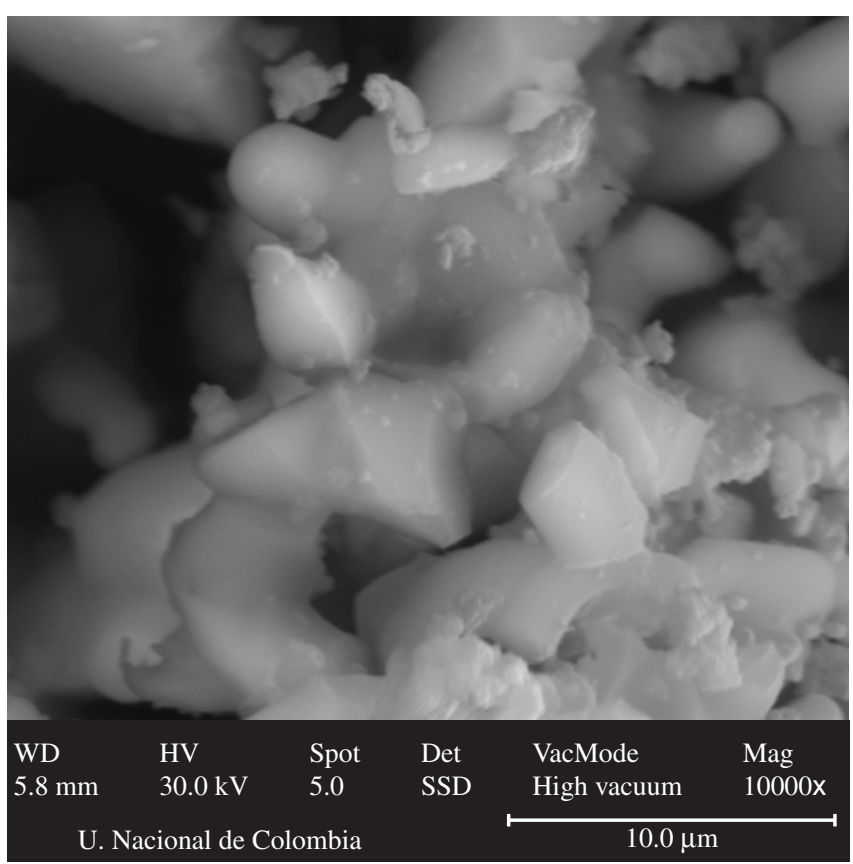

Figure 6. 10,000 magnification SEM of sintered HA6.

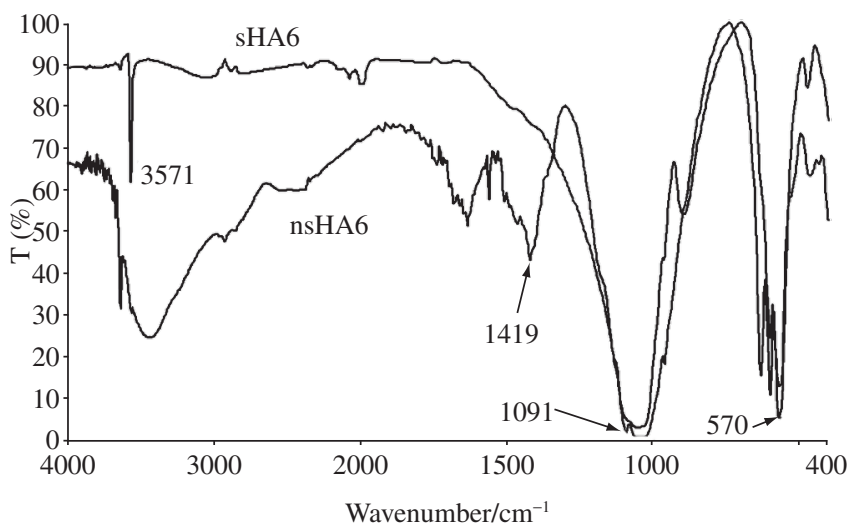

Figure 7. FTIR spectra of nsHA6 and sHA6. 
and water in the sample $\left(3400-3200 \mathrm{~cm}^{-1}\right)$, which is very noticeable for nsHA6 but almost inexistent for sHA6 because the latter had been recently sintered while the former had not. For upper curve spectroscopic grade $\mathrm{KBr}$ pellet background was substracted in order to better observe inherent final product features.

Lower curve band at 1636 is originated in a $\mathrm{KBr}$ absorption. The nsHA6 bands at 1419 and $896 \mathrm{~cm}^{-1}$ are caused mainly by the asymmetric in plane stretching and out of the plane bending modes of $\mathrm{CO}_{3}=$ respectively ${ }^{7}$. These two bands disappeared in sinter indicating that carbonate was eliminated by heat treatment.

Absorptions at 1091, 1044 (v3) and shoulder at 960 (v1) are characteristic for phosphates as well as those at 601 and $570 \mathrm{~cm}^{-1}$ (v4). The band at $631 \mathrm{~cm}^{-1}$ is attributed to an $\mathrm{OH}$ ion libration ${ }^{22}$. HPO4 = can be identified by a band at $870 \mathrm{~cm}^{-1}$ in calcium defficient apatites $^{7,21}$ and that band is absent in sHA6. In short, sHA6 generates an FTIR spectrum that is characteristic of hydroxyapatite and contains no indication of carbonate or $\mathrm{HPO}_{4}=$ content.

XRF elemental analysis of calcium hydroxide detected five minor elements (Al, Si, S, Zn and Sr). PA specifications state traces of several elements, most of them below a few parts per million (ppm) or even less. Out of the five above mentioned traces only $\mathrm{S}$ and $\mathrm{Zn}$ $(0.0007 \%$ and $0.0002 \%)$ arise from PA. In sHA6 the same five elements were found. Two of these elements might come from alumina balls or porcelain milling tank: $\mathrm{Al}$ and Si. Silicon remained virtually constant in both samples $(0.099 \%)$ that is before and after milling. Aluminum increased from $0.052 \%$ in calcium hydroxide to $0.224 \%$ in sHA6 implying that milling device does slightly impair product's composition. Sulphur, zinc and strontium percent concentrations in sHA6 were $0.010,0.003$ and 0.010 respectively and do not significantly differ from those in calcium hydroxide.

\section{Conclusions}

Four phases constitute all the six methods' raw products namely calcium hydroxide, TCP, HA and CaHPO4 regardless of the range of applied conditions. Calcium hydroxide and CaHPO4 disappear during sintering because they react following various reactions that increase HA or TCP content. Calcium hydroxide also disappears by dehydration forming calcium oxide. In method number $6 \mathrm{TCP}$, calcium hydroxide and CaHPO4 react without residue to form only HA.

Slow PA addition favors cold HA formation in raw mixtures. Quick PA addition works in the opposite direction, it cuts down HA formation. Mechanical paddle stirring time slightly improves reaction, it exerts a less important effect than addition time and is insufficient for reaching a thorough homogeneity. One hour milling promotes HA final content but 6 hours are necessary for making a nearly uniform dispersion of raw product suitable for a complete thermally activated reaction. Heating is necessary for a complete reaction. Six hours (or even a few more) wet milling do not complete the reaction. Solid to liquid proportion is a determining factor in directing reaction towards high purity HA. Solid to liquid ratio influence is much larger than that of quick PA addition. There is no complete reaction without a thorough homogeneity and a thermal activation. An abridged method for producing highly pure monophasic HA in substantial amounts has been established.

\section{Acknowledgements}

The authors express their acknowledgements to Division de Investigaciones DIB de la sede Bogotá de la Universidad Nacional de Colombia for the financial support of this project.

\section{References}

1. Dorozkhin SV, Epple M. Biological and Medical Significance of Calcium Phosphates. Angew Chem. Int. Ed. 2002; 41(17):3130-3146.
2. Vallet M, González J. Calcium Phosphates as Substitution of Bone Tissues. Progress in Solid State Chemistry. 2004; 32 (1-2):1-31.

3. Witte F, Feyerabend F, Maier P, Fisher J, et al. Biodegradable MagnesiumHydroxyapatite Metal Matrix Composites. Biomaterials 2007; 28(13):2163-2174.

4. Khairoun I, Driessen FCM, Boltong MG, Planell JA, Wenz R. Addition of Cohesion Promotors to Calcium Phosphate Cements. Biomaterials 1999; 20(4):393-398.

5. Yamamoto H, Niwa S, Hori M, Hattori T, Sawai K, Aoki S, Hirano M, Takeuchi H. Mechanical Strength of Calcium Phosphate Cement in Vivo and in Vitro. Biomaterials 1998; 19(17):1587-1591.

6. Barralet JE, Grover GT, Wright AJ, Gibson IR. Preparation of Macroporous Calcium Phosphate Cement Tissue Engineering Scaffold. Biomaterials 2002; 23(15):3063-3072.

7. Elliott JC. Studies in inorganic chemistry 18 . Structure and chemistry of the apatites and other calcium orthophosphates. Amsterdam: Elsevier Science; 1994.

8. Santos MH, Oliveira M, Palhares L, Mansur HS, Vasconcelos WL. Synthesis Control and Characterization of Hydroxyapatite Prepared by Wet Precipitation Process. Materials Research 2004; 7(4):625-630.

9. Villora JM, Callejas P, Barba MF. Métodos de Síntesis y Comportamiento Térmico de la Hidroxiapatita. Boletín de la sociedad española de cerámica $y$ vidrio 2002; 41(4):377-384.

10. Orlovskii VP, Komlev VS, Barinov SM. Hydroxyapatite and Hydroxyapatite-Based Ceramics. Inorganic Materials 2002; 38(10):1159-1172.

11. El Briak-BenAbdeslam H, Ginebra MP, Vert M, Boudeville P. Wet or Dry Mechanochemical Synthesis of Calcium Phosphates? Influence of the Water Content on DCPD-CaO Reaction Kinetics. [article accepted 11 july 2007/In press]. Acta Biomateralia.

12. Destainville A, Champion E, Bernache-Assollant D, Laborde E. Synthesis, characterization and Thermal Behaviour of Apatitic Tricalcium Phosphate. Materials Chemistry and Physics 2003; 80(1):269-277.

13. Wantae K, Fumio S. Sonochemical Synthesis of Hydroxyapatite from $\mathrm{H}_{3} \mathrm{PO}_{4}$ Solution with $\mathrm{Ca}(\mathrm{OH})_{2}$. Ultrasonics Sonochemistry 2001; 8(2):85-88.

14. Deepak K, Pattanayak RD, Prasad RC, Rao BT, Rama M. Synthesis and Sintered Properties Evaluation of Calcium Phosphate Ceramics. Materials Science and Engineering C 2007; 27(4):684-690.

15. Ashis B, Amit B, Susmita B. Hydroxyapatite nanopowders: Synthesis, Densification and Cell-materials Interaction. Materials Science and Engineering 2007; 27(4):729-735.

16. Zhang J, Gao X, Song B, Wang Z, Lu W. A Novel Technique to Synthesize Hydroxyapatite Whiskers. [article accepted 31 july 2007/In press]. Materials Letters.

17. Ishida MA, VolkmerTM, Dos-Santos, LA. Efeito da adiçao de defloculante na precipitaçao de hidroxiapatita sintética. Proceedings of the III Latin American Congress on artificial organs and biomaterials COLAOB; 2004 July 27-30; Campinas, SP, Brasil: Faculdade de Engenharia Mecânica, Universidade de Campinas; 2004. p. 97.

18. Fook C, Moyer H. Quantitative chemical analysis, an introduction to the science and practice of chemical measurement. Toronto: Mc Graw hill; 1952.

19. Clavijo-D A. Fundamentos de química analítica: quilibrio iónico y análisis químico. 1 ed. Bogotá: Universidad Nacional de Colombia; 2002.

20. ICCD - International Centre for Diffraction Data. PC-PDF. Powder Diffraction File-2. Card retrieval/display system. JCPDS. Release 2006 $R D B$. Available from:<http://www.iccd.com $>$.

21. Coreño J, Coreño O, Cruz JJ, Rodriguez C. Mechanochemical Synthesis of Nanocrystalline Carbonate-substituted Hydroxyapatite. Optical Materials 2005; 27(7):1281-1285.

22. Peña J, Vallet-Regi M. Hydroxyapatite, Tricalcium Phosphate and Biphasic Materials Prepared by a Liquid Mix Technique. J. Eur. Ceram. Soc. 2003; 23(10):1687-1696. 